\title{
Biobank consent models - are we moving toward increased participant engagement in biobanking?
}

This article was published in the following Dove Press journal:

Journal of Biorepository Science for Applied Medicine

23 July 2015

Number of times this article has been viewed

\section{Berge Solberg \\ Kristin Solum Steinsbekk \\ Department of Public Health and General Practice, Norwegian University of Science and Technology (NTNU), Trondheim, Norway}

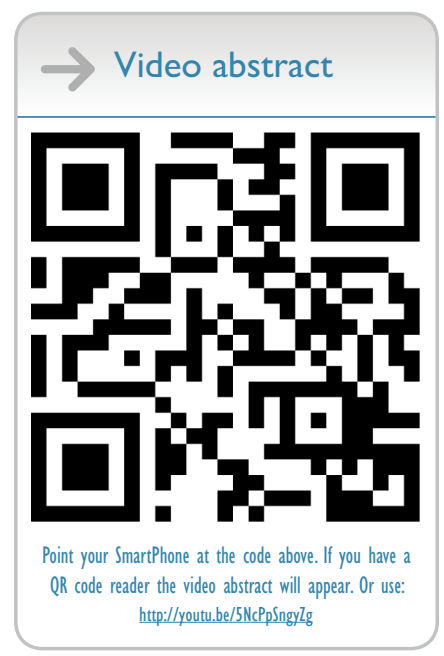

Correspondence: Berge Solberg Department of Public Health and General Practice, Norwegian University of Science and Technology (NTNU), Postbox 8905,

Trondheim 749I, Norway

Tel +47 73597587

Email berge.solberg@ntnu.no
Abstract: Engagement, involvement, and active participation are buzzwords used in today's ethical debate on research biobanking. There are a variety of context-sensitive governance frameworks for research biobanks. However, many biobanks, especially large-scale population-based ones, seem to endorse a framework of broad consent, participation with minimal or no ongoing engagement, and no return of results. An alternative vision of involvement and active participation in this type of research has become increasingly visible in the literature. The problem, seen from the biobankers' perspective, is that the alternative vision might be costly, cumbersome, and risky, while the prevailing system for governance will maximize the scientific value of the biobank with minimal ethical, legal, and social efforts. Therefore, solid and convincing arguments are needed to determine if biobank institutions should take a radical step toward more ongoing engagement and donor involvement. In this paper, we review the arguments found in articles addressing dynamic consent, participatory research, reciprocity, and participant engagement in biobank research. We identify four core ideas on which the arguments for increased involvement are based. The strength of the arguments are then analyzed. We conclude that despite challenges with increased engagement, there seem to be substantial reasons to increase participant engagement in biobanking.

Keywords: biobank ethics, participatory research, dynamic consent, reciprocity

\section{Background}

For nearly two decades biobankers, ethicists, and regulators have struggled with governance, the concept of informed consent, and the nature of participation in large-scale research biobanking. Numerous debates on appropriate ethical frameworks have taken place because the idea of collecting biological specimens and associated data from a vast number of people, as a resource for biomedical research, have materialized in many countries worldwide. ${ }^{1-11}$ One of the important factors influencing both biobank establishment and ethical debate is the technological revolution within genetics and genomics.

A consensus has not been reached for any of the topics above. However, for large population-based research biobanks, in practice it seems that one particular consent model is used, which we will call "the dominant model". In the dominant model, the so-called "broad consent" is the basis for the activity. ${ }^{12-15}$ A "broad consent" is the opposite of a study-by-study (or specific) consent when it comes to detailed information about specific research projects. It means that participants consent to storage and downstream use of their human biological material and health data. ${ }^{12-15}$ The use is deemed "broad" because material and information can be used in numerous projects 
without obtaining a new consent, as long as the projects are within those initial broadly defined boundaries. Further, in the dominant model, usually there would be no return of individual research results and a low (or no) level of interaction or direct engagement with the individual biobank participant after biological material and data initially are collected. Many large-scale, population-based biobanks, eg, the UK Biobank, British Columbia Biobank, and CARTaGENE, have had several consultative initiatives with lay people and the public before their startup. ${ }^{16-20}$ After this initial phase, when such biobanks are established they engage with individual participants mainly through a variant of the dominant model of consent when they are recruited. ${ }^{13}$

This model is practical and convenient for research logistics and researchers, and giving a broad consent at least seems to indicate a positive attitude toward future research activities. At the same time, some ethicists would argue that broad consent, a one-time initial consent, "deviates from hallmarks of informed consent as enshrined in ... research ethics", as Allen et al describe it. ${ }^{12}$ The reason is that the broader the consent is and the longer it is in time since it was given, the more compatible it is with a situation where participants in a research biobank do not know much about what is going on, to what they consented, for what their sample and data are used, with whom their data are shared, and what the researchers know about them. ${ }^{6,12,14,15,21,22}$ The information biobanks are able to give their participants at the time of enrollment is seldom sufficient for meeting conventional standards of informed consent at a later stage. In order for a broad consent to be continuously "informed", it must be followed up by comprehensive and continuous information, but this is often far from the reality in large-scale biobanks.

So, even if broad consent has solved some problems for the research biobank(s), it has on the other hand triggered renewed consent debates based on its shortcomings. 4,6,7,12,15,17,23-27 Better information and communication routines would be one plausible and simple response to this challenge. However, some would argue that this is not enough; that we have to rethink the relationship between researchers and research participants is one of the claims. Here the visions of increased engagement and a closer relationship enter the picture. Basically, this is about how we are "constructing" or "making up" research subjects, as Tutton and Prainsack have noted. ${ }^{28}$ Research subjects within the commercial direct-to-consumer genetic testing company 23 andMe, for instance, are "constructed" differently than research subjects within the UK Biobank. ${ }^{28,29}$ While "altruism" is a central element of the framing of participation in the UK Biobank, "entrepreneurialism" is a better term for how participation is constructed in 23 andMe, according to these authors. ${ }^{28}$

Our aim here is not only sociological but also normative, ie, to try to state which construction of the research subjects in today's large-scale biobanking is the most ethical. Are there good ethical reasons for biobanks to engage more actively with their participants and to change their consent models? And if so, what are those reasons according to the literature?

The authors of this paper have previously defended the broad consent model in combination with "passive participation" and no return of research results. We argued that broad consent is a perfectly valid consent and that passive participation and no return of results is an ethical acceptable position because it avoids any risk of harming participants. ${ }^{10,30,31}$ However, we wanted to challenge this position by looking into claims and insights of an increasing body of literature on the engagement of individual biobank participants in biobank research.

\section{Knowledge basis}

In this paper, we wanted to explore and analyze the moral landscape for participant engagement in biobank research. In order to characterize that landscape, we tried to identify most of the papers written on this topic. The relevant academic papers were identified by using the search engines PubMed, Scopus, and ISI Web of Science. We searched for papers including the words "biobank", "biobanks", or "biobanking" in the title, abstract, or keywords, in combination with "engagement", "participation", "participatory", "partnership", "partners", "reciprocity", or "dynamic consent". We did not search for papers on "consent" or "informed consent", because much of the consent debate has nothing to do with participation, engagement, or involvement. One exception to this is the term "dynamic consent", because it is directly linked to the debate on ongoing engagement in biobank research. We also stayed away from search terms like "stakeholders". We believe that much of the stakeholder literature has focused on public engagement and consultations with lay people prior to the establishment of biobank institutions (like in the UK Biobank), whereas the focus in this paper is on the nature of participation in ongoing biobank activity.

Based on these search parameters, we first identified more than 400 unique papers. After a quick examination of titles and abstracts, we were able to exclude irrelevant papers outside the domain of biobank ethics. Further on, papers with abstracts that did not thematize some form of participant engagement in biobank research were deemed of low 
interest. We were then left with 115 papers, 52 of which are referenced to in this article. These 115 papers were published between 2004 and May 2015, with over 75\% of these being published within the last 5 years. This shows that the question of defining the appropriate nature of biobank participation first becomes urgent when large-scale biobanks worldwide are up and running. It also coincides with the point in time where new and extensive genome technologies have been introduced.

\section{Critiques of the lack of participant engagement in research biobanking}

Most of the papers deemed relevant for our scrutiny point out challenges with the current dominant consent or engagement model, and as such have an ambition to initiate change. In this respect, they all represent some form of normative criticism, ie, criticism toward the lack of involvement of individual participants and toward the passive, broad consent model currently used in large-scale, population-based biobank research. When analyzing the arguments and the content of the included articles, we found that they could be divided into four main categories. We used the term "critique" when labeling the three first categories. The criticisms differ, and our aim was to articulate the essence of the different types of criticism. We ended up with the following headings for our three categories: choice-based critique, reciprocity critique, and political critique. In addition, one class of arguments is centered around the benefits for biobank research based on an active participation model. We labeled this category "the utility perspective". We now reveal what ideas and argumentative landscapes are hidden behind these four headings.

\section{Choice-based critique}

One way to resolve the endless discussion on consent models in biobank research is to forget about the philosophical arguments on what proper informed consent in biobank research entails. Instead, biobanks could use a consent model that donors prefer. Several studies have tried to capture the consent preferences of donors. ${ }^{32-41}$ One problem with these studies is that people disagree with regard to consent preferences. In a study by Platt et al, 52\% of participants preferred broad consent over study-by-study consent models. ${ }^{34}$ However, they also found a higher preference for study-by-study consent in certain ethnic and social groups. In a study by Simon et al, up to $67 \%$ of respondents preferred a prospective opt-in over an opt-out consent approach. ${ }^{35}$ At the same time, broad, research-unspecific consent was preferred over study-specific consent models for purposes of approving future research. Although these two studies show a fairly high preference for broad consents, other studies such as the large Eurobarometer from 2010 show different outcomes. ${ }^{37}$ Thus, not everybody agrees. So where does this leave us in terms of study-by-study or broad consent? Whose preferences should become the basis for policy? And how can we really know that people's consent preferences are stable? What if participants change their minds? What if societal changes affect biobank research or scandals like breach of privacy make participants change their preferences?

These questions can in fact be answered within what we have termed "the choice-based critique". This entails the fact that we should be able to deal with many different consent preferences in biobank research. One way of dealing with different consent preferences is captured in the "dynamic consent" model. Dynamic consent, in the way it is presented by Kaye et al, Wee, Erlich et al, and Thiel et al, implies, among other things, that donors and participants are given choices in the consent process. ${ }^{7,25,42,43}$ In the digital age, dynamic consent can be built into the technological infrastructure of the biobank, and different consent preferences can easily be satisfied. In that way, it is possible to facilitate more autonomous choices within large-scale biobank research and respect the decision-making process of the individual. 7,15,21,24,27,44

The whole point of the dynamic consent model is of course to be dynamic. That means that donors should have control over their consent, be able to track and inspect it, as well as change it whenever it suits the individual donors. ${ }^{15,24}$ Proponents of such a consent model also argue that by being able to exercise a dynamic, flexible, and ongoing consent, research participants have control over samples and data. ${ }^{7,24,25,34,40,45}$ If participants get tired and burdened by a study-by-study consent, but still want to endorse biobank research, then they should be able to change their consent preference to a broad(er) consent, thereby ensuring all preferences are met.

We have called this position "the choice-based critique", considering that a central dimension of being a citizen in a liberal democracy is having choices and the possibility to satisfy different preferences. The dynamic consent model can satisfy those preferring a study-by-study consent, broad consent, or switching between the consent models. All consent options are available on a menu, hence also under the label "menu consent", 34,46 This position represents a critique of the established broad consent model because broad consent only respects the preferences of a certain share of a potential study population. The dynamic consent model represents "deep respect" according to Wee. ${ }^{24}$ The respect is "deep" 
partly because a range of different preferences are accepted and respected and partly because this means that participants' ability to exert control over their data are increased compared to the broad consent model. The ability to exert control is not only increased in the initial consent setting but also increased longitudinally since dynamic consent should be an ongoing process. . $21,24,25,42,45$ Being in control, having more choices, having a platform that enables individuals to be closer to the ideal of autonomy, and thus getting more respect for different preferences, are all part of the choice-based critique of the dominating framing of biobank governance today, including the use of broad consent models.

\section{Reciprocity critique}

Biobank research studies samples from human subjects and their associated data. It is a certain distance, both in time and physical location, between the sample donation and the subsequent research. The distance in time is often several years, and the research is often distributed to research collaboration nationally and internationally. This separates research participants from the researchers in a different manner when compared with other forms of more interactive biomedical research, like clinical trials. Therefore, it is easier for the researchers to overlook the fact that biobank research is still a form of investigation involving people. Saha and Hurlbut point out, "Current practices in managing biobanks tend to see the public as little more than a resource for mining data and materials, and as a potential source of resistance" ${ }^{47}$ There seems to be an asymmetrical or even lack of a bidirectional relationship between research participants and research communities.

Lack of symmetry in the researcher-participant relationship also expresses a lack of reciprocity. The participants give answers, data, biological material, and time to the researchers, but they do not get anything back. Now, of course the task of medical research is to "give back" better health care in the future, as a result of the research effort. But, in addition to that, research on humans in general always faces the question of reciprocity here and now. Gottweis et al have expressed this point as follows: "People need to feel that they are part of something larger and that their donation feeds into a mutual, respectful relationship. This cannot be done simply by talking in abstract terms about the potentially significant medical benefits that might result from biobank research at some unspecified point in the future." 48 Thus, according to Gottweis et al, promises of medical advances in the future are not enough to express the kind of reciprocity that most people want: "Certainly, medical advances are relevant, but research shows that participants in many countries expect individual feedback from check-ups and also expect the possibility of gaining information about research advances that result from the biobanks in which they are participating, as long as their tissue or DNA is part of the biobank. They rarely expect money in return, but want to be appreciated as donors and be treated well." ${ }^{\text {48 }}$

What participants could get back, then, include for instance research results, incidental findings, and other therapeutic benefits. There is an ongoing dispute about the benefits (and potential harm) of returning research results and incidental findings in research. ${ }^{49-56}$ However, independent of the controversy on incidental findings, participants could get back something absolutely uncontroversial from the researchers and the biobank institutions: they could receive more information on the research they are involved in, gain a greater insight into their own role in the scientific enterprise, and be introduced to the controversies within science, for instance on genomics, privacy, and so on. ${ }^{57}$ Many would argue that there is an intrinsic value in knowing what science is, what it can and cannot achieve, and at least those that are actually taking part in scientific endeavors should be given the chance to understand. ${ }^{7,57}$ As Beskow et al write: "Although many people have high expectations for biomedical research, they often have a limited understanding of the incremental steps involved in generating new knowledge. One widely underestimated aspect of the research process is the amount of time required to translate a specific research observation into generalizable knowledge of sufficient validity and reliability to inform a medical test or other health intervention." ${ }^{57}$

"Scientific literacy" is a central slogan in what we have called "the reciprocity critique". The prevailing model of broad consent and low interaction with participants is criticized because science leaves participants in scientific illiteracy. ${ }^{7}$ The reciprocity critique stresses that more balance is needed in the relationship between researchers and participants. When participants give something valuable to the researchers, the researchers should feel an obligation to give something in return. If the reciprocity critique is taken seriously and acted upon, the claim is that this could lead toward a real engagement between donors and the research institution, and thus develop a more robust biobank research because the potential for controversy is reduced.

Internet-based, web 2.0, communication platforms could be a strategy to mend some of these shortcomings in the asymmetrical relationship between researchers and research 
participants in biobank research. Such platforms have the potential to empower the individual research participants and to treat them more as partners in the endeavor of biobank research, ${ }^{12,15,45,47}$ and give the donor an opportunity to stay connected to and be informed about biobank research.

\section{Political critique}

"The political critique" is voiced in a category of literature highlighting the transformative potential of large-scale research biobanking. In short, the thesis here is that biobank research changes society. Societal changes are essentially what politics and democracy are all about. Therefore, in order to "democratize science", citizens and participants should be part of the governance of large-scale biobanks that influence radical changes in our society.

Such a political critique has several facets. One of the major drivers in biobank research is large epidemiological studies using genetic or genomic information. Today, huge initiatives and consortiums use data and biological materials from thousands of individuals. In addition to an appropriate consent, community review, and consultation, an appropriate partnership between biobank participants and research biobanks is called for. ${ }^{15,47}$

From this perspective, not only is consent based on preferences or a bidirectional ongoing relationship between research and researchers required, but active roles in decision-making and shaping of biomedical research priorities are essential. ${ }^{15,47,58-63}$ The purpose is "to give power to the people" and to make biobank initiatives and biobank research robust and successful. . $^{3,47,64,65}$ According to Burgess, over the past 20 years we have seen a shift from a mode where the research community just tells the research participants to "trust them" to an involved mode where representatives from the public participate in policy decisions. ${ }^{58}$ The public is important and able to "co-produce policy and standards of practice that are technically informed". ${ }^{58}$ The public can contribute to incorporate wide social perspectives and be involved in key decisions. Different ways to engage people in this political sense could involve conducting widespread consultations through focus groups, social media, community advisory boards, and newsletters. ${ }^{18,61,63,64,66-73}$

The political critique entails voices that go beyond a consultation approach. McNamara, Petersen, and Gottweis, among others, have been proponents of a more radical political critique. ${ }^{74,75}$ They argue that public consultations are not sufficient. Rather, the ambition should be to "provide citizens with an opportunity to transform policy and practice" as McNamara and Petersen write. ${ }^{75}$ According to these authors, the consultation model will appear from this perspective to be superficial because it is often "based on the so-called deficit model of public understanding that assumes that any opposition or lack of engagement is due to the 'public's' ignorance of the project and its benefits, which can be corrected through the changing of view via more or better information". ${ }^{75}$

Common for the political critique, then, is the focus on the importance of participant engagement in biobanks since biobanks have a large, transformative potential. Biobanks, according to Gottweis and Petersen, "incorporate visions for the future of medicine and healthcare, ... interaction with pharmaceutical industry and embed images of the patient, the citizen, collective identity and society". ${ }^{74}$ The implication is that participants should be included in such a change of society. The more radical implication is that participants, as well as citizens in general, should be able to question and oppose those trends in development they see as problematic.

\section{Utility perspective}

The fourth category is not a moral critique of the lack of ongoing participant involvement in biobank research. Rather, it is a perspective highlighting the benefit and utility for biobank researchers to establish a closer relationship with its donors.

Dynamic interactive consent is an effective way to recontact, reconsent, and collect additional data or samples from research participants and thereby serves the interests of researchers. ${ }^{7,24,42,43,47}$ It is a platform that enables effective ways for bidirectional communication. It has the potential to keep the biobank donors updated continuously. As Beskow et al write, it is also possible to include features taken from marketing to promote "customer loyalty" as "opportunities to ask questions and live feedback, and/or hosting of online interactive discussions". ${ }^{57}$ The proponents of dynamic consent also see it as a tool to "strengthen the therapeutic relationship with patients" because it enables the return of research-generated results to the individual research participant in his or her own preferred manner. ${ }^{24}$

Even in projects where there is no return of individual research results, engagement with participants might be beneficial by being a building block for trust. According to Beskow et al: "Ultimately, scientists who create and maintain genomic biobanks are stewards of those materials and the trust that is essential to their continued existence." "R7 "Regular communication of aggregate results could foster participant trust in genomic research by reporting outcomes, explaining how a particular study is positioned in the translational pathway, and potentially soliciting participant feedback on questions 
of importance to effective research (eg, procedures intended to foster recruitment and retention). Regular updates about research progress - including the inevitable setbacks and challenges - can help to forge the types of relationships critical to informed trust in the research enterprise." 57

"Participatory research" is a buzzword today. Researchers and research participants can move closer to each other and form an alliance that everyone could benefit from. By "giving back", biobank researchers would seem to act in their own interests as well as in those of participants. The claim is thus a win-win situation. On the one hand, there is a potential for participants to take a more active role in shaping biomedical research, as seen in examples of the active roles played by a number of patient and disease advocacy organizations in supporting various forms of research. ${ }^{15,24,26,47,76}$ On the other hand, "giving back" might foster loyalty, trust, and easier access to participants, which is important when new issues arise. As Chalmers et al state: "[T] as key partners, may result in them becoming champions for future recruitment or further data collection." ${ }^{26}$ Currently "genotype-driven recruitment" in biobank research is emerging as a scientifically promising albeit ethically challenging strategy. ${ }^{77-80}$ Here recontact and re-engagement with participants of interest is essential.

The utility perspective stresses that it is in the interest of biobank institutions to establish ongoing engagement with participants. ${ }^{15}$ This will be a partnership that is not only profitable to the research participant but also could be deemed to be even more profitable to biobank research in itself. This as a closer more bidirectional relationship is claimed to help biobank research by its ability to retain participants, reduce the administrative hassle involved in recruiting participants, and help to create appropriate cohorts needed in biomedical research. ${ }^{15} \mathrm{~A}$ dynamic bidirectional relationship hopes to foster an increase in trust between the partners, and thus strengthen the possibilities that lie within biobank research.

\section{Discussion}

We have identified an increasing amount of literature dealing with engagement in biobank research. This is not surprising as the established large biobanks are gradually ready for use. Thus, it is now time to grapple with how to frame the research participant in this endeavor. We have divided the arguments into four different categories. The issue now is what strengths and weaknesses do we find within these argumentative landscapes.

\section{Choice-based critique}

The strength of this model is its ability to satisfy different preferences. For instance, on the question of consent, participants would be able to choose between broad consent or study-by-study consent. They could choose to change their consent preferences at any time. The same goes for preferences on the flow of information (eg, subscription to newsletters), involvement, recontact, return of results, incidental finding, and so on. With regard to all the questions that bioethicists have been disagreeing on (eg, "is study-by-study-consent better than broad consent?"), the participants are, in the choice-based model, given the choices themselves, thereby taking control over their own samples and data and their way of participating and engaging in the biobank endeavor.

The weakness of this critique is that it is not entirely clear why we, in this arena, have to introduce choices in the first place. Although potential participants in a survey are able to express differences in preferences with regard to consent, return of results, and information intensity, the question is still whether such preferences are "deep" and important enough to pay attention to. The alternative approach would be a "take it or leave it" approach: Either you participate on our premises (eg, with this type of consent or this type of return-of-result policy), place trust in the system of biobank research and its researchers, or you do not participate at all. What is the problem with such an approach?

One obvious problem is that it restricts choice. As the philosopher Gerald Dworkin remarked, we very often take for granted that more choices are always better than less. ${ }^{81}$ More choices seem to make us more autonomous than fewer choices. But, on the other hand, this is not more than a general rule of thumb, he argues. Sometimes new choices add additional costs, change the initial option, pressure us to conform, and so on. "In the realm of choice, as in all others, we must conclude enough is enough." 81

The question then for biobank research is whether it is enough to be able to choose to participate or not, or whether more choices would add to our autonomy. More choices in biobank research could perhaps be costly and cumbersome, and it is far from obvious that participants play the same role as citizens do in other arenas where choices are directly linked to more autonomy and freedom. Therefore, we seem to need weightier reasons to introduce a choice model or a menu model than just the implicit assumption that more choices are better than less. Could these weightier reasons come from the other critique categories? 


\section{Reciprocity critique}

The strength of the reciprocity critique is its intuitiveness. When participants give something valuable to the researchers, it seems intuitively correct that researchers should give something back if they possess something valuable to the participants. Valuable items could include information, scientific insight and knowledge, research results, and incidental findings. Although it is convenient for researchers and biobanks to treat donors only as a historical resource, this critique says they should feel a duty to engage and interact with donors in order to avoid any kind of exploitation of research participants.

The weakness of this critique is that it neglects what research is all about. Research is usually not for the participants. Medical research in general, and biobank research in particular, has a long-term focus where future patients are the recipients of today's research effort. Medical research gives back in the sense that existing and future health care services are based on insights from past and present medical research. Therefore, engaging too much with participants takes resources and focus away from the real obligation of researchers, which is to maximize the research effort in order to give back to patients in the future. To quote Levitt, "The costs and benefits of closer contact have to be weighed up carefully". ${ }^{2}$ As Nicol and Critchley have remarked, there are two competing norms here: “... the norm of social responsibility on the one hand, and the norm of reciprocity on the other." ${ }^{\$ 3}$ There is a risk of undermining the norm of social responsibility by highlighting reciprocity as a key value in research.

Having said that, it is still relevant to question what researchers owe current research participants. The argument that reciprocity is ensured by transformation of research to health care services is equally valid for participants and nonparticipants. It cannot be used to brush aside the reciprocity critique entirely. In all types of research, reciprocity also seems to mean something within the research process and not only outside of it.

The fact that biobank research is a longitudinal endeavor where people are participants for decades, maybe for the rest of their lives and even beyond, seems to imply that some kind of relationship does or should exist between participants and biobanks. Donors and their biological material and information should not merely be perceived as raw materials for research. Reciprocity is absolutely a relevant point of departure to try to articulate the nature of the relationship between participants and biobank research.

\section{Political critique}

The strength of the political critique is its ability to give a "deep" justification for why engagement and active participation are important in biobank research. In classical medical research, ethical questions dealing with consent and privacy are important, but from a political standpoint they sometimes seem to take away focus from the bigger picture. The bigger picture is about who should be informed about, and decide upon, how science changes society. And the answer from the political critique is that at least those who participate in a game-changing endeavor like large-scale biobank research should be able to influence and raise their voices.

The weakest point of this type of critique, in our view, is that although it has a "deep" justification, it seem too idealistic. People may engage in activities that relate to them. This is a necessary but far from sufficient premise. Even in activities that largely relate to people, it is often hard to create engagement, eg, in local politics, school activities, and local sports clubs. The challenge with biobank research is that it probably is far down on the list of what people feel directly relates to them, unless the participants are patients themselves or the next of kin of patients with serious diseases. In addition, it is a complex and complicated activity that needs extra effort to be understood. So even if Burgess are correct about a general trend from "trust us" to direct user involvement, it is not necessarily true that this is relevant for large-scale biobanking. ${ }^{58}$

An additional challenge for the political critique is what type of tools we could use in order to engage participants and stakeholders in the daily life of biobanking. Probably the easiest way to succeed with participant involvement is through focus group interviews, surveys, and other consultations. Several biobanks have done more or less intensive forms of public engagement prior to their establishment, among them the UK Biobank in the UK, SharDNA in Italy, and BC Biobank in Canada. ${ }^{17-19}$ However, the more radical critics, like McNamara and Petersen, warn against a consultation approach, which primarily works, according to them, by giving increased legitimacy to biobank research: "There is little scope for those participating in the surveys or forums or for broader publics to offer assessment of the overall validity of the science and of the scientists' visions, and the longer-term economic, social and political implications of the project or of biobanking more generally". ${ }^{75}$ So even though surveys and focus groups are "doable", they far from satisfy a more radical version of the political critique.

However, this critique can also be turned around: even though we can imagine a critical public discourse "where the 
overall validity of the science and of the scientists' visions, and the longer-term economic, social and political implications of the project or of biobanking more generally" are discussed, it seems far from doable, at least from within the biobank community. ${ }^{75}$ It is hard to imagine a biobank trying to facilitate and initiate a critical political discussion that could potentially undermine its own existence. The short history of large-scale biobanking has shown us that strong political engagement primarily arises from disagreement and controversies, like the history of deCode genetics in Iceland. Such political engagement probably arises and thrives better outside of what it scrutinizes.

The political critique stresses that large-scale biobank research has a political dimension and participants should be able to influence it. There is disagreement within the camp whether consultation initiatives are examples of a more democratic science or if they just add legitimacy to a predetermined science where the form and content is decided elsewhere.

\section{Utility perspective}

The utility perspective differs from the other categories in the sense that it is not a critique and it is not primarily an ethical perspective. Rather, the motivation here is to increase engagement with donors in order to pave the way for new research design and hence more and better research. The utility perspective suggests that in order to maximize the research potential in large-scale biobanks and genomics (which could be claimed to be an ethical imperative), researchers should be able to recontact participants easily as well as continuously monitor consenting individuals. Doing so of course presupposes that such activity is ethically acceptable and compatible with the interest of the donors. As Tutton and Prainsack remarked, this is where 23andMe has been able to persuade its customers/ donors that the company (the research institution) and the participants have common interests. ${ }^{28}$ Whether this is true or not could be a matter of dispute. But as both research and technology within genomics advances, the potential for biobank research to produce findings meaningful for individuals increases. When this happens, utility and reciprocity meet, and the biobankers have to reflect upon what researchers owe research participants.

\section{Weighing arguments}

We started our search for literature and arguments with an intention to challenge our own position. Earlier we defended the dominant model with a broad consent combined with passive participation in large-scale biobank research and no return of results. Have the three different types of criticism against this position made us change our minds?

Few people would deny that there are important and reasonable insights here. The dynamic consent approach is of course quite right in its criticism of the lack of meaning in historical consents. Nobody remembers 15 years later what they consented to, not even the researchers or the research institution. In addition, few would deny that reciprocity and benefit sharing are relevant values in biobank research, as in medical research in general. Further, it is hard to deny that the transformative potential of large-scale research biobanking, genomics, and personalized medicine should be topics to discuss and engage with, at least by those whose genomes are sequenced in research.

However, broad consent, passive participation, and no return of results, including a good and comprehensive communication strategy, can still be argued to comply with good ethics. Restricting participants' choices does not have to mean that the biobank institution is not giving them information. Withholding incidental findings from research does not exclude other types of reciprocity and caring for research participants. Further, not consulting research participants regularly does not exclude the possibility for research biobanks to facilitate ethicopolitical discourses on biobanks, genomics, and personalized medicine.

At least in theory, broad consent, passive participation, and no return of results seem to be compatible with the three different categories of critique that we have described. This position can even be backed up by an ethical claim that "solidarity" and not "autonomy" should be the dominant frame for the relationship between participants and biobanks. ${ }^{84}$ However, there is a risk here that this framework works better in theory than in practice; a challenge with this model could be the lack of incentives, motivations, or visions for the research institution to treat participants as more than suppliers of raw material for research in practice. ${ }^{47}$ Broad consent and a lack of other motivational values for increased involvement might easily become a pretext for not informing, not asking, and not engaging. An ethical reference to "solidarity" may be convenient for not spending resources on information, involvement, and communication. This will work at least as long as the historical consent is valid and no fundamentally "new questions" arise in the biobank (eg, introduction of commercial partners, introduction of new controversial technologies, new demands on data sharing in international databases, and new designs that may affect the return of results policy). However, when "new" questions suddenly arise, the biobank needs to contact its donors, and 
the whole question of what kind of relationship this really represents is revived. The weakness of the dominant model, then, is its tendency to lag behind when important questions arise instead of being proactive and at the forefront. By not having a vision or conviction on the proper engagement of participants, by not seeing the value of reciprocity, and by not having a thoughtful strategy for communication, it is probably harder for research biobanks to address important ethical and political questions before they arise.

This last point also links to the fourth category, ie, the utility perspective. Biobank research will in the future probably benefit from closer contact with their donors. The flow of information, recontact, controversial research designs, and reconsent is made easier when there is an open line of communication between researchers and participants. When biobank researchers realize they need to stay in closer contact with their donors, "solidarity" is probably not enough to secure the interest of the donors. "Solidarity" should then be complemented by "reciprocity".

\section{Conclusion}

We have managed to show that there is a rapidly increasing literature on the importance of engagement and active participation in biobank research. Further, we have identified three different categories of critiques against the dominant way of governing large-scale biobanks today. The dominant model was criticized from what we called a choice-based position (too few options and too little autonomy and control), from a reciprocity position (giving without receiving), and from a political perspective (blind acceptance, no discussion).

As skeptical readers of this literature, we still find the three perspectives important and interesting. Our main objection to the choice-based position is the lack of "deep" justification for why more choices is better than less in this arena. A menu of choices in a restaurant is obviously a good thing, but a menu of choices when participating in research may seem misguided. Our main objection to the political critique is its idealistic character. We struggle to understand how the criticism, in the radical form, can be "implemented" effectively within the biobank community.

On the other side, we are convinced that reciprocity is a universal research ethical value. Reciprocity is important in order to avoid exploitation. In addition, it is a value that inspires and encourages biobank institutions to take the relationship with their participants seriously. We can disagree on whether the principle of reciprocity obliges us to return, for instance, incidental findings to research participants. However, we cannot disagree on the fact that reciprocity puts us under some kind of obligation toward research participants. By making reciprocity the "core organizing principle" for large-scale biobanking, as Gottweis et al have proposed, we would ensure at least that the ethical framework of a biobank continuously motivates the research institution to define and establish a good and proper relationship between participants and the biobank..$^{48}$ In the near future, more research biobanks will probably see the benefit of closer contact with their donors. If that happens, reciprocity would become even more important as a guiding value in treating participants with proper respect.

The dominant model of broad consent written down on a piece of paper, which almost nobody is able to access later on, seems quite old-fashioned when compared with what can be obtained by digital communication and social platforms. Even though more choices is not necessarily better than less, more transparency, more participant control over his or her data, and better accessibility to targeted knowledge and information seems to be better than less. Our study has shown that there is a trend in the literature toward recommending increased participant engagement in biobank research. There seem to be irresistible elements involved, both from critical and utility perspectives, in a dynamic consent approach with more donor involvement. Our discussion here has shown that there are good reasons to take this trend seriously.

\section{Disclosure}

The authors report no conflicts of interest in this work.

\section{References}

1. Clayton EW. Informed consent and biobanks. J Law Med Ethics. 2005; 33(1):15-21.

2. Greely HT. The uneasy ethical and legal underpinnings of large-scale genomic biobanks. Annu Rev Genomics Hum Genet. 2007;8(1): 343-364.

3. Greely HT. Breaking the stalemate: a prospective regulatory framework for unforseen research uses of human tissue samples and health information. Wake Forest Law Rev. 1999;34(3):737-766.

4. Hansson MG, Dillner J, Bartram CR, Carlson JA, Helgesson G. Should donors be allowed to give broad consent to future biobank research? Lancet Oncol. 2006;7(3):266-269.

5. Hoeyer K, Olofsson BO, Mjörndal T, Lynöe N. The ethics of research using biobanks: Reason to question the importance attributed to informed consent. Arch Intern Med. 2005;165(1):97-100.

6. Hofmann B. Broadening consent - and diluting ethics? J Med Ethics. 2009;35(2):125-129.

7. Kaye J, Whitley EA, Lund D, Morrison M, Teare H, Melham K. Dynamic consent: a patient interface for twenty-first century research networks Eur J Hum Genet. 2015;23(2):141-146.

8. Lunshof JE, Chadwick R, Vorhaus DB, Church GM. From genetic privacy to open consent. Nat Rev Genet. 2008;9(5):406-411.

9. Sheehan M. Can broad consent be informed consent? Public Health Ethics. 2011;4(3):226-235.

10. Steinsbekk KS, Myskja BK, Solberg B. Broad consent versus dynamic consent in biobank research: is passive participation an ethical problem? Eur J Hum Genet. 2013;21(9):897-902. 
11. Caulfield T, Kaye J. Broad consent in biobanking: reflections on seemingly insurmountable dilemmas. Med Law Int. 2009;10(2):85-100.

12. Allen C, Joly Y, Moreno PG. Data sharing, biobanks and informed consent: a research paradox? McGill Journal of Law and Health. 2013;7(1):85-120.

13. Master Z, Nelson E, Murdoch B, Caulfield T. Biobanks, consent and claims of consensus. Nat Methods. 2012;9(9):885-888.

14. Petrini C. "Broad" consent, exceptions to consent and the question of using biological samples for research purposes different from the initial collection purpose. Soc Sci Med. 2010;70(2):217-220.

15. Kaye J, Curren L, Anderson N, et al. From patients to partners: participant-centric initiatives in biomedical research. Nat Rev Genet. 2012;13(5):371-376.

16. Godard B, Marshall J, Laberge C, Knoppers BM. Strategies for consulting with the community: the cases of four large-scale genetic databases. Sci Eng Ethics. 2004;10(3):457-477.

17. Artizzu F. The informed consent aftermath of the genetic revolution. An Italian example of implementation. Med Health Care Philos. 2008; 11(2):181-190.

18. O'Doherty KC, Burgess MM. Engaging the public on biobanks: outcomes of the BC biobank deliberation. Public Health Genomics. 2009; 12(4):203-215.

19. Levitt M, Weldon S. A well placed trust? Public perceptions of the governance of DNA databases. Crit Public Health. 2005;15(4): 311-321.

20. Avard D, Bucci LM, Burgess MM, et al. Public health genomics (PHG) and public participation: points to consider. Journal of Public Deliberation. 2009;5(1):21.

21. D'Abramo F. Biobank research, informed consent and society. Towards a new alliance? J Epidemiol Community Health. February 10, 2015. [Epub ahead of print].

22. Salvaterra E, Lecchi L, Giovanelli S, et al. Banking together. $E M B O$ Rep. 2008;9(4):307-313.

23. Stein DT, Terry SF. Reforming biobank consent policy: a necessary move away from broad consent toward dynamic consent. Genet Test Mol Biomarkers. 2013;17(12):855-856.

24. Wee R, Henaghan M, Winship I. Dynamic consent in the digital age of biology: online initiatives and regulatory considerations. J Prim Health Care. 2013;5(4):341-347.

25. Erlich Y, Williams JB, Glazer D, et al. Redefining genomic privacy: trust and empowerment. PLoS Biol. 2014;12(11):e1001983.

26. Chalmers D, Burgess M, Edwards K, Kaye J, Meslin EM, Nicol D. Marking shifts in human research ethics in the development of biobanking. Public Health Ethics. September 5, 2014. [Epub ahead of print.]

27. Grady C. Enduring and emerging challenges of informed consent. N Engl J Med. 2015;372(9):855-862.

28. Tutton R, Prainsack B. Enterprising or altruistic selves? Making up research subjects in genetics research. Sociol Health Illn. 2011;33(7): 1081-1095

29. Harris A, Wyatt S, Kelly SE. The gift of spit (and the obligation to return it). How consumers of online genetic testing services participate in research. Information Communication and Society. 2012;16(2): 236-257.

30. Steinsbekk KS, Solberg B. Biobanks - when is re-consent necessary? Public Health Ethics. 2011;4(3):236-250.

31. Solberg B, Steinsbekk KS. Managing incidental findings in population based biobank research. Nor Epidemiol. 2012;21(2):195-201.

32. Gaskell G, Gottweis H, Starkbaum J, et al. Publics and biobanks: panEuropean diversity and the challenge of responsible innovation. Eur J Hum Genet. 2013;21(1):14-20.

33. Kaufman D, Bollinger J, Dvoskin R, Scott J. Preferences for opt-in and opt-out enrollment and consent models in biobank research: a national survey of Veterans Administration patients. Genet Med. 2012;14(9): 787-794.

34. Platt J, Bollinger J, Dvoskin R, Kardia SL, Kaufman D. Public preferences regarding informed consent models for participation in population-based genomic research. Genet Med. 2014;16(1):11-18.
35. Simon CM, L'Heureux J, Murray JC, et al. Active choice but not too active: public perspectives on biobank consent models. Genet Med. 2011;13(9):821-831.

36. Trinidad SB, Fullerton SM, Bares JM, Jarvik GP, Larson EB, Burke W. Informed consent in genome-scale research: what do prospective participants think? AJOB Prim Res. 2012;3(3):3-11.

37. Gaskell G, Stares S, Allansdottir A, et al. Europeans and Biotechnology in 2010. Winds of Change? Brussels, Belgium: European Commission; 2010 .

38. Lewis C, Clotworthy M, Hilton S, et al. Consent for the use of human biological samples for biomedical research: a mixed methods study exploring the UK public's preferences. BMJ Open. 2013;3(8).

39. Hoeyer K. Donors perceptions of consent to and feedback from biobank research: time to acknowledge diversity? Public Health Genomics. 2010;13(6):345-352.

40. Kelly SE, Spector TD, Cherkas LF, Prainsack B, Harris JM. Evaluating the consent preferences of UK research volunteers for genetic and clinical studies. PLoS One. 2015;10(3):e0118027.

41. Tupasela A, Sihvo S, Snell K, Jallinoja P, Aro AR, Hemminki E. Attitudes towards biomedical use of tissue sample collections, consent, and biobanks among Finns. Scand J Public Health. 2010;38(1):46-52.

42. Wee R. Dynamic consent in the digital age of biology. J Prim Health Care. 2013;5(3):259-261

43. Thiel DB, Platt J, Platt T, et al. Testing an online, dynamic consent portal for large population biobank research. Public Health Genomics. 2015;18(1):26-39.

44. Williams H, Spencer K, Sanders C, et al. Dynamic consent: a possible solution to improve patient confidence and trust in how electronic patient records are used in medical research. JMIR Med Inform. 2015;3(1):e3.

45. Mont MC, Sharma V, Pearson S. EnCoRe: dynamic consent, policy enforcement and accountable information sharing within and across organisations. HP Laboratories Technical Report, 2012. Available from: http://www.hpl.hp.com/techreports/2012/HPL-2012-36.pdf. Accessed June 4, 2015.

46. Murphy J, Scott J, Kaufman D, Geller G, LeRoy L, Hudson K. Public perspectives on informed consent for biobanking. Am J Public Health. 2009;99(12):2128-2134.

47. Saha K, Hurlbut JB. Research ethics: treat donors as partners in biobank research. Nature. 2011;478(7369):312-313.

48. Gottweis H, Gaskell G, Starkbaum J. Connecting the public with biobank research: reciprocity matters. Nat Rev Genet. 2011;12(11):738-739.

49. Bledsoe MJ, Grizzle WE, Clark BJ, Zeps N. Practical implementation issues and challenges for biobanks in the return of individual research results. Genet Med. 2012;14(4):478-483.

50. Wolf SM, Crock BN, Van Ness B, et al. Managing incidental findings and research results in genomic research involving biobanks and archived data sets. Genet Med. 2012;14(4):361-384.

51. Viberg J, Segerdahl P, Langenskiold S, Hansson MG. Freedom of choice about incidental findings can frustrate participants' true preferences. Bioethics. April 23, 2015. [Epub ahead of print.]

52. Ferriere M, Van Ness B. Return of individual research results and incidental findings in the clinical trials cooperative group setting. Genet Med. 2012;14(4):411-416.

53. Jarvik GP, Amendola LM, Berg JS, et al. Return of genomic results to research participants: the floor, the ceiling, and the choices in between. Am J Hum Genet. 2014;94(6):818-826.

54. Steinsbekk KS, Solberg B. Should genetic findings from genome research be reported back to the participants? Tidsskr Nor Laegeforen. 2012;19(132):2190-2193

55. Fisher R. A closer look revisited: are we subjects or are we donors? Genet Med. 2012;14(4):458-460.

56. Murphy J, Scott J, Kaufman D, Geller G, LeRoy L, Hudson K. Public expectations for return of results from large-cohort genetic research. Am J Bioeth. 2008;8(11):36-43.

57. Beskow LM, Burke W, Fullerton SM, Sharp RR. Offering aggregate results to participants in genomic research: opportunities and challenges. Genet Med. 2012;14(4):490-496. 
58. Burgess MM. From 'trust us' to participatory governance: deliberative publics and science policy. Public Underst Sci. 2014;23(1):48-52.

59. Gottweis H, Lauss G. Biobank governance: heterogeneous modes of ordering and democratization. J Community Genet. 2012;3(2):61-72.

60. Gottweis H, Lauss G. Biobank governance in the post-genomic age Pers Med. 2010;7(2):187-195.

61. Haddow G, Cunningham-Burley S, Bruce A, Parry S. Generation Scotland: consulting publics and specialists at an early stage in a genetic database's development. Crit Public Health. 2008;18(2):139-149.

62. Molster C, Maxwell S, Youngs L, et al. An Australian approach to the policy translation of deliberated citizen perspectives on biobanking. Public Health Genomics. 2012;15(2):82-91.

63. O’Doherty KC, Burgess MM, Edwards K, et al. From consent to institutions: designing adaptive governance for genomic biobanks. Soc Sci Med. 2011;73(3):367-374.

64. Dove ES, Joly Y, Knoppers BM. Power to the people: a wiki-governance model for biobanks. Genome Biol. 2012;13(5):158.

65. Hawkins AK, O'Doherty K. Biobank governance: a lesson in trust. New Genet Soc. 2010;29(3):311-327.

66. Hobbs A, Starkbaum J, Gottweis U, Wichmann HE, Gottweis H. The privacy-reciprocity connection in biobanking: comparing German with UK strategies. Public Health Genomics. 2012;15(5):272-284.

67. Lemke AA, Wu JT, Waudby C, Pulley J, Somkin CP, Trinidad SB Community engagement in biobanking: experiences from the eMERGE Network. Genomics Soc Policy. 2010;6(3):35-52.

68. McCarty CA, Garber A, Reeser JC, Fost NC. Study newsletters, community and ethics advisory boards, and focus group discussions provide ongoing feedback for a large biobank. Am J Med Genet A. 2011;155a(4):737-741.

69. McWhirter RE, Critchley CR, Nicol D, et al. Community engagement for big epidemiology: deliberative democracy as a tool. $J$ Pers Med. 2014;4(4):459-474.

70. O'Doherty KC, Hawkins AK, Burgess MM. Involving citizens in the ethics of biobank research: informing institutional policy through structured public deliberation. Soc Sci Med. 2012;75(9):1604-1611.

71. Papaioannou T. From consultation to deliberation? A qualitative case study of governing science and technology projects for the public good. Crit Public Health. 2012;22(2):235-251.
72. Platt JE, Platt T, Thiel D, Kardia SLR. 'Born in Michigan? You're in the Biobank': engaging population biobank participants through Facebook advertisements. Public Health Genomics. 2013;16(4):145-158.

73. Simon CM, Newbury E, Heureux JL. Protecting participants, promoting progress: public perspectives on community advisory boards (CABs) in biobanking. J Empir Res Hum Res Ethics. 2011;6(3):19-30.

74. Gottweis H, Petersen A. Biobanks and governance: an introduction. In: Gottweis H, Petersen A, editors. Biobanks: Governance in Comparative Perspective. New York, NY, USA: Routledge; 2008.

75. McNamara B, Petersen A. Framing consent: the politics of 'engagement' in an Australian biobank project. In: Gottweis H, Petersen A, editors. Biobanks: Governance in Comparative Perspective. New York, NY, USA: Routledge; 2008.

76. Landy DC, Brinich MA, Colten ME, Horn EJ, Terry SF, Sharp RR. How disease advocacy organizations participate in clinical research: a survey of genetic organizations. Genet Med. 2012;14(2):223-228.

77. Hall SS. Genetics: a gene of rare effect. Nature. 2013;496(7444): 152-155.

78. Budin-Ljøsne I, Soye KJ, Tassé AM, Knoppers BM, Harris JR. Genotype-driven recruitment: a strategy whose time has come? BMC Med Genomics. 2013;6(1).

79. Beskow LM, Linney KN, Radtke RA, Heinzen EL, Goldstein DB. Ethical challenges in genotype-driven research recruitment. Genome Res. 2010;20(6):705-709.

80. Beskow LM, Fullerton SM, Namey EE, Nelson DK, Davis AM, Wilfond BS. Recommendations for ethical approaches to genotypedriven research recruitment. Hum Genet. 2012;131(9):1423-1431.

81. Dworkin G. The Theory and Practice of Autonomy. Cambridge, UK: Cambridge University Press; 1988.

82. Levitt M. Relating to participants: how close do biobanks and donors really want to be? Health Care Anal. 2011;19(3):220-230.

83. Nicol D, Critchley C. Benefit sharing and biobanking in Australia. Public Underst Sci. 2012;21(5):534-555.

84. Prainsack B, Buyx A. A solidarity-based approach to the governance of research biobanks. Med Law Rev. 2013;21(1):71-91.
Journal of Biorepository Science for Applied Medicine

\section{Publish your work in this journal}

The Journal of Biorepository Science for Applied Medicine is an international, peerreviewed, open access journal that focuses on new developments and advances in the emerging and evolving field of biorepository science. This includes biospecimen procurement, processing, preservation, and banking for application to applied medicine. The Journal invites submission of manuscripts which address these aspects in addition to systems logic, clinical throughput and ethical issues pertaining to application of

\section{Dovepress}

biorepositories and their effects on clinical medicine. The journal is characterized by the rapid reporting of reviews, original research, methodologies, technologies and analytics in this subject area. The manuscript management system is completely online and includes a very quick and fair peer-review system, which is all easy to use. Visit http:/ www.dovepress.com/testimonials.php to read real quotes from published authors. 